\title{
Achieving Landscape-Scale Deer Management for Biodiversity Conservation: The Need to Consider Sources and Sinks
}

\author{
KRISTIN WÄBER, ${ }^{1}$ School of Environmental Sciences, University of East Anglia, Norwich NR4 7TJ, UK \\ JONATHAN SPENCER, Principal Adviser Natural Environment, Forestry Services, Forestry Commission England, 620 Bristol Business Park, \\ Bristol BS16 1EJ, UK \\ PAUL M. DOLMAN, School of Environmental Sciences, University of East Anglia, Norwich NR4 7TJ, UK
}

\begin{abstract}
Hyper-herbivory following predator removal is a global issue. Across North America and Europe, increasing deer numbers are affecting biodiversity and human epidemiology, but effectiveness of deer management in heterogeneous landscapes remains poorly understood. In forest habitats in Europe, deer numbers are rarely assessed and management is mainly based on impacts. Even where managed areas achieve stable or improving impact levels, the extent to which they act as sinks or persist as sources exporting deer to the wider landscape remains unknown. We present a framework to quantify effectiveness of deer management at the landscape scale. Applied across $234 \mathrm{~km}^{2}$ of Eastern England, we assessed management of invasive Reeve's muntjac (Muntiacus reevesi) and native roe (Capreolus capreolus), measuring deer density (using thermal imaging distance transects $780 \mathrm{~km} /$ year), fertility, neonatal survival, and culling to quantify source-sink dynamics over 2008-2010. Despite management that removed 23-40\% of the annual population, 1,287 (95\% CI: 289-2,680) muntjac and 585 (454-1,533) roe deer dispersed annually into the wider landscape, consistent with their ongoing range expansion. For roe deer, culled individuals comprised fewer young deer than predicted by a Leslie matrix model assuming a closed population, consistent with agedependent emigration. In this landscape, for roe and muntjac, an annual cull of at least $60 \%$ and $53 \%$, respectively, is required to offset annual production. Failure to quantify deer numbers and productivity has allowed high density populations to persist as regional sources contributing to range expansion, despite deliberative management programs, and without recognition by managers who considered numbers and impacts to be stable. Reversing an unfavorable condition of woodland biodiversity requires appropriate culls across large contiguous areas, supported by knowledge of deer numbers and fertility. (c) 2013 The Wildlife Society.
\end{abstract}

KEY WORDS Capreolus capreolus, evidence-based conservation, invasive species, landscape-scale, Muntiacus reveesi, source-sink dynamics.

Across much of North America and Europe, growing deer numbers are of increasing concern (DeCalesta 1994, Dolman and Wäber 2008, Newson et al. 2012). In modified landscapes that provide high quality food and lack large predators, deer populations are projected to increase further (Ward 2005, Suominen and Danell 2006). Deer have severe impacts on woodland biodiversity, altering structure (Martin et al. 2010, Holt et al. 2011, Newson et al. 2012), reducing woodland bird abundance (Holt et al. 2011, Martin et al. 2011), modifying small mammal (Buesching et al. 2011) and invertebrate (Allombert et al. 2005) assemblages, and affecting ecosystem functions including carbon storage (Tanentzap

Received: 24 June 2012; Accepted: 26 November 2012

Additional supporting information may be found in the online version of this article.

${ }^{1}$ E-mail:k.waeber@uea.ac.uk and Coomes 2012). Currently high deer numbers threaten to jeopardize proposals to mitigate carbon emissions through increased woodfuel production (Fuller and Rothery 2010) and are a vector for Lyme disease (Hartfield et al. 2011), with implications for human health. In Europe, fatalities and injuries from deer-related road traffic accidents are increasing, with vehicle damage costing more than 1 billion dollars annually (Bruinderink and Hazebroek 1996, Apollonio et al. 2010). To control such impacts, deer management is necessary (Department for Environment, Food \& Rural Affairs [DEFRA] and Forestry Commission 2010).

To be accountable and defensible to the public, deer management should be based on robust, verifiable evidence. Although fencing can alleviate local problems and overand underpasses can reduce problems at collision hotspots (Glista et al. 2009), management at landscape or regional scales requires lethal control (Department for Environment, Food \& Rural Affairs [DEFRA] and Forestry Commission 
2010). Effective control requires targets, estimates of numbers before and after culling, population forecasting, and monitoring of outcomes. However, examples of integrated monitoring and management are scarce in wildlife management (Mayle 1996, Chee and Wintle 2010). Although thermal imaging distance sampling now offers a technique to quantify deer numbers across different contiguous landscape units (Gill et al. 1997, Hemami et al. 2007), estimating deer density is often considered prohibitively difficult (Gaillard et al. 2003, Zannèse et al. 2006). Management, therefore, is based on subjective perceptions of abundance, deer condition, or on impact levels (e.g., Morellet et al. 2007, Mysterud et al. 2010). However, as impacts are context-dependent and nonlinearly related to densities (Koda and Fujita 2011, Putman et al. 2011, Tanentzap et al. 2012), their assessment does not translate readily into cull targets. When deer numbers are unknown, reducing impacts may require progressive increases in the annual numbers killed and is further hindered by slow ecosystem recovery (e.g., Tanentzap et al. 2009, 2011). Crucially, when enhanced culls have reduced numbers from an unknown high, to an unknown lesser level, the subsequent control level needed to constrain impacts within desired bounds is unknown, unless population assessment is undertaken. Consequently, deer management often proceeds based on guesswork, particularly in Europe.

A further complication surrounds issues of scale and spatial population structure. In some countries or regions, individual deer management units cover extensive regional landscapes (e.g., Norway, with the largest municipality $9,000 \mathrm{~km}^{2}$ in extent; see Apollonio et al. 2010). In contrast, in much of Europe and parts of the eastern United States, regional landscapes comprise heterogeneous mosaics overlain by complex hunting rights and patterns of land ownership (Apollonio et al. 2010, Putman 2012). Dispersal and population flux among contiguous landholdings may obscure or overwhelm responses to site-specific culls (Putman 2012). Where management is insufficient relative to local reproductive potential, local impacts or perceived numbers may nevertheless remain stable if deer emigrate (Fig. 1). Management may then proceed on the false assumption that cull levels are appropriate, exporting problems to the wider landscape. Conversely, if the cull exceeds local production to deplete deer from the wider landscape, this may not be recognized if immigration results in stable levels of impact and perceived numbers (Fig. 1). The implications of such source-sink dynamics have not been appreciated by deer managers, but have likely been key in the failure to limit expanding populations, particularly of introduced species (Ward 2005, Newson et al. 2012). Robust and scientifically credible management models must be developed based on an understanding of local numbers, productivity at landscape scales, offtake by managers, and the magnitude of landscapescale population flux.

In a unique study for Europe, we investigated source-sink flux of 2 deer species, roe deer (Capreolus capreolus) and Reeve's muntjac (Muntiacus reevesi), among individual forest

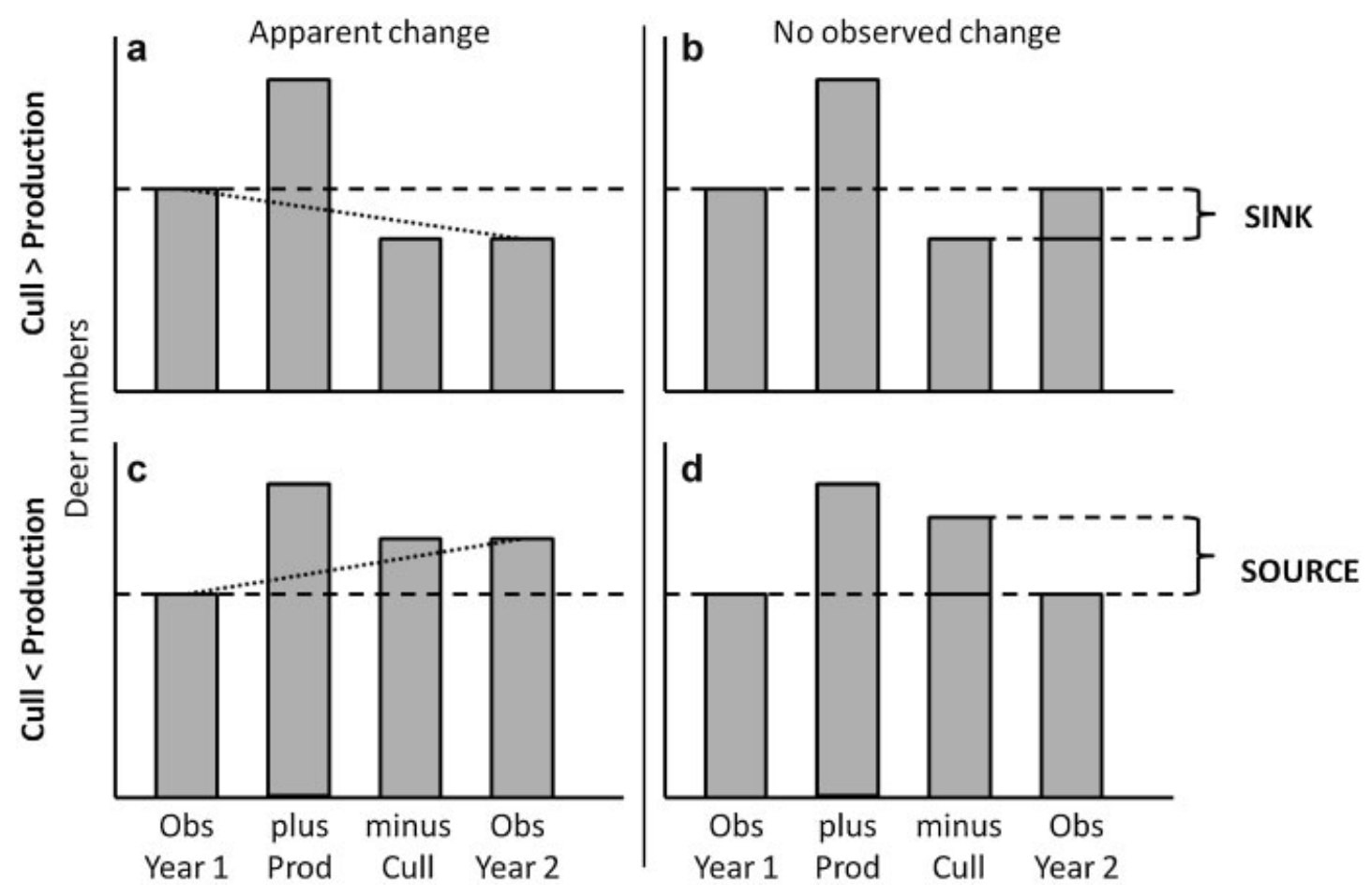

Figure 1. Different potential population outcomes of deer culling. Vertical bars represent total deer density, after the sequential action of breeding, culling, and any migration. Potential population size in the absence of migration is predicted from the initial deer density in year 1 (Obs Year 1), increased by reproduction (plus Prod; product of proportion of reproductive active females, fertility, and neonatal survival), but is then reduced by culling (minus Cull). This is compared to observed density in year 2 (Obs Year 2). If cull exceeds potential productivity (a and b), then density may either decrease (a) or remain stable (b), depending on relative migration rates. Conversely, if the cull is less than local productivity ( $\mathrm{c}$ and $\mathrm{d}$ ) so that managers must increase cull quotas to stabilize regional numbers, the observed local density may either increase (c) or remain stable (d) depending on whether excess individuals settle locally or emigrate. 
blocks, across contiguous forested and grass-heath landscapes totaling $234 \mathrm{~km}^{2}$. To determine whether current cull targets based on incomplete knowledge were sufficient to prevent further population growth, we measured deer numbers, annual production, neonatal survival, and cull mortality. We then compared the potential magnitude of population growth to density measured in subsequent years, to assess whether net immigration or emigration had occurred, and thus whether these managed landscapes were net sources or sinks for deer.

\section{STUDY AREA}

We considered forested and grass-heath landscapes within Breckland, Eastern England $\left(52^{\circ} 30^{\prime} \mathrm{N}, 0^{\circ} 60^{\prime} \mathrm{W}\right)$, which has a semi-continental climate and sandy soils (Dolman et al. 2012). Thetford Forest $\left(195 \mathrm{~km}^{2}\right)$ is dominated by Corsican (Pinus nigra) and Scots pine (Pinus sylvestris; totaling $67 \%$, with other conifers $4 \%$, deciduous trees $10 \%$, and open areas $19 \%$ of the forest area) and is managed by clearfelling and replanting of even-aged stands (Eycott et al. 2006) creating a mosaic of growth stages. The forest is subdivided by roads into 12 blocks (mean area $=15.6 \pm 10.2 \mathrm{~km}^{2} \mathrm{SD}$, range $4.5-34.7 \mathrm{~km}^{2}$ ), of which 7 totaling $132 \mathrm{~km}^{2}$ were monitored in this study. The grassheath landscape (Stanford Practical Training Area) is a military training area (managed by the Defence Estates [DE]) extending over $102 \mathrm{~km}^{2}$ contiguous with 3 of the monitored forest blocks. It primarily comprises extensively sheep-grazed grass heath (60\%), arable (18\%), deciduous woodland (13\%), and conifer plantations (3\%).

Within Thetford Forest, deer are primarily managed by professional Forestry Commission wildlife rangers, with 1 forest block $\left(24 \mathrm{~km}^{2}\right)$ leased to a private stalking club and another $\left(9.6 \mathrm{~km}^{2}\right)$ partly managed by a private estate. Cull targets in Forestry Commission managed blocks were previously based on perceived abundance, recently supported by dung-based population and thermal imaging surveys, with individual forest blocks re-surveyed approximately every 4 years, with control also responsive to forestry damage assessments. Over 2007-2010, a mean annual cull of 2,244 individuals ( $\pm 202 \mathrm{SD}$ ) or 11.5 deer per $\mathrm{km}^{2}$ was achieved. Grassheath populations are managed by stalkers from the Defence Estate. Until 2008, culls were based on subjective assessment of numbers, with a mean annual cull of 273 individuals $( \pm 77$ SD) over 2001-2008; from 2009 to 2010, estimates from this study were incorporated into the cull plan, which increased the mean annual cull to 499 individuals ( \pm 11 SD) in 20102011.

\section{METHODS}

\section{Identification of Sub-Population Sources and Sinks}

We calculated potential population growth for each landscape and individual forest blocks from initial numbers, plus net annual production calculated from measures of fertility, the proportion of reproductive females in the population, and neonatal survival, minus culled numbers. This allowed an assessment of whether culls were sufficient to reduce num- bers at either the landscape-scale or within individual forest blocks. We examined source-sink dynamics comparing potential population growth (or decline) to observed changes in deer numbers from year $t$ to $t+1$. For roe, births occur from April to June; therefore, we defined years from 1 April to 31 March of the following calendar year. We estimated density in January-March; numbers in year $t$ support productivity in year $t+1$. We calculated the potential number of deer that may be immigrating or emigrating $\left(\mathrm{PN}_{\mathrm{EmIm}}\right)$ from a landscape unit $i$ (forested or grass-heath landscape, or individual forest block) as

$$
\mathrm{PN}_{\mathrm{EmIm}}=\left(N_{\mathrm{obsit}}+P_{i t+1}-M_{i t+1}\right)-N_{\mathrm{obsit}+1}
$$

where for each landscape unit $i, N_{\text {obsit }}$ represented the observed number in year $t, P_{i t+1}$ was the annual production in year $t+1, M_{i t+1}$ was the cull in year $t+1$, and $N_{\text {obsit }+1}$ was the observed number in year $t+1$.

A negative value, with observed numbers in year $t+1$ greater than could be achieved through in situ production offset by the cull, indicates net immigration with the landscape unit acting as a sink. Conversely, a positive value, with observed numbers in year $t+1$ less than the potential population that could have been achieved, indicates net emigration and a potential source (Fig. 1). Whether potential sources result in dispersal of individuals to adjoining landscapes or blocks depends on levels of other unmeasured mortality. Based on an extensive network of local informants including the Forestry Commission, estate managers, and game keepers, poaching was negligible, and remains expected from disease or other natural mortality were rarely encountered despite extensive ecological fieldwork. Recorded road traffic accidents involving roe and muntjac totaled 181 in 2008-2009 and 105 in 2009-2010.

\section{Density Measurement}

We assessed densities of muntjac and roe deer in the forest in 2008, 2009, and 2010 and in the grass-heath landscape in 2009 and 2010, using nocturnal thermal imaging distance sampling (Gill et al. 1997, Hemami et al. 2007) during January to March. We conducted 1-sided transect surveys from 2000 hours to 0400 hours using a thermal imager (FLIR Systems, Inc., Wilsonville, OR), from the front passenger seat of a 4-wheel-drive vehicle driven at a maximum speed of $16 \mathrm{~km} / \mathrm{hr}$ on the widespread trackway network, and measured perpendicular distances with a laser range finder mounted with a night vision (Maxi-Kite Mk 4; THALES optics, St. Asaph, United Kingdom) fitted with an infrared illuminator.

In the forested landscape, we drove a mean of $529 \mathrm{~km}( \pm 40$ $\mathrm{SD})$ each year, with variation due to felling management. In the grass-heath landscape, we drove the same transects totaling $250 \mathrm{~km}$ each year. Observations of 2,625 muntjac and 1,725 roe deer in the forested and 310 muntjac and 274 roe deer in the grass-heath landscape, provided robust detection functions. We used distance analysis (Buckland et al. 2001) for each species in each landscape using DISTANCE 6.0 release 2 (Thomas et al. 2010). In the forest, we pooled detectability across years but stratified it by forest block to 
account for consistent differences in vegetation density when estimating annual density for each block. In the grass-heath, we pooled detectability across years to estimate annual landscape-wide density.

We examined variation in density among the 7 individual forest blocks and the grass-heath landscape (factor), and between years (covariate) using a generalized linear model (GLM) with normal error, with the interaction between block and year used to test whether the spatial pattern of density was stable between years. We investigated differences among blocks using the sequential Sidak test.

\section{Measurement of Demographic Parameters}

We obtained data for all animals culled over 2001-2010 for both landscapes from the Forestry Commission and Defence Estates (larder data), including the date shot, location, sex, age (for roe: juvenile, yearling, adult), body mass, and fertility (fetus per female). Professional Forestry Commission stalkers collected cull data in the forest landscape. In the grass-heath, we retained cull data from known expert stalkers. For this study, starting in the 2006 cull year, data protocols for fertility records were improved. Thus, we calculated age structure and fertility for the forest landscape from 2006 to 2009 and for the grass-heath from 2007 to 2009.

Age and sex structure and age-specific fertility.We determined the sex composition of each roe deer subpopulation from thermal imaging data, and age structure from larder data. From April, we classified juvenile roe born the previous year as yearlings and all previous cohorts as adults ( $\geq 2$ years). Yearling roe do not give birth, but may mate during summer to subsequently calve in their first adult year. To examine whether these 2-year-olds are less fertile than older females, we compared fertility between overwintering yearlings and adults.

Roe deer embryos in the early stages of development may be missed on inspection of the uterus (Ratcliffe and Mayle 1992) because of delayed implantation (Aitken 1974). We calculated apparent fertility rates in larder data from the forested landscape from December to the close of hunting in February using a GLM with Poisson error, controlling for age class (adult vs. yearling) and cull year (2006-2009). Fertility rates did not increase after mid January $(n=567$, $\chi_{1}^{2}=173.17, P<0.001$, sequential Sidak test $P<0.001$ ). Therefore, we determined roe fertility from females culled from week 6 .

We determined muntjac sex composition during thermal imaging, but as age-specific tooth eruption patterns are unknown (Chapman et al. 1985), we defined age classes from the relation of fertility to body mass. Among females culled in the forested landscape $(n=1,172,2006-2009)$, fertility increased up to $7 \mathrm{~kg}$ in body mass (GLM with Poisson error: Wald $\chi_{5}^{2}=123.80, P<0.001$, sequential Sidak test $P<0.001)$. We defined female muntjac with a larder mass $\geq 7 \mathrm{~kg}$ as reproductively mature (hereafter adult); females between $5 \mathrm{~kg}$ and $7 \mathrm{~kg}$ as reproductively active subadults, and females $<5 \mathrm{~kg}$ as non-reproductive juveniles. Muntjac are aseasonal breeders (Chapman 1991); therefore, we calculated the annual mean fertility of adult or sub-adult female muntjac $\left(F_{\mathrm{MJ}}\right)$, assuming a reproductive cycle of 7 months (see Appendix A and Figure A.1, available online at www.onlinelibrary.wiley.com), as

$$
F_{\mathrm{MJ}}=\frac{12 \text { month }}{7 \text { month }} \times F_{\mathrm{A} / \mathrm{SA}}
$$

where $F_{\mathrm{A}}$ and $F_{\mathrm{SA}}$ are the mean fertility of adult and subadult females per parturition event. The annual mean fertility of reproductive active females is weighted by the proportion of adult and sub-adult females.

Neonatal mortality.-For roe, we estimated neonatal survival from birth to first winter by comparing observed autumn kid-female ratios with larder measures of fertility (fetus per female). Forestry Commission rangers recorded kids, yearlings, and adult female numbers in each roe group observed from 1 October to the end of November, for 10 forest blocks covering $173 \mathrm{~km}^{2}$; they recorded 481 groups (169 in 2007, 176 in 2008, 136 in 2009) comprising 477 adult females and 611 kids. The number of repeated observations within these data are unknown, but we considered it small relative to the number of groups counted. Number of kids was positively related to the number of adult females in the family group ( $n=481$ groups, GLM with Poisson error: Wald $\chi_{1}^{2}=25.73, P<0.001$ ), with no differences among cull years (2007-2009: Wald $\left.\chi_{2}^{2}=2.53, P=0.28\right)$ or forest blocks (Wald $\chi_{10}^{2}=10.67, P=0.38$ ). The pooled mean juvenile-female ratio was 1.24 juveniles per adult female \pm 0.68 (SD). We calculated neonatal survival of roe deer kids $\left(S_{\mathrm{K}}\right)$ from birth to their first winter as

$$
S_{\mathrm{K}}=1-\left[\frac{F-K F}{(F)}\right]
$$

where $F$ is the mean fertility (per female) from larder data for January-February 2006-2009 and $K F$ the kid-female ratio in October-November 2007-2009.

For aseasonally breeding muntjac, kid-female ratios cannot be used to infer neonatal survival rates. Therefore, we estimated survival rates by calculating the expected proportions of pregnant and or lactating females using plausible biological parameters (for gestation duration, rate of fetus development, duration of lactation, and timing of subsequent pregnancy), under different assumptions of kid mortality, and comparing these to the proportions observed in larder data (adults with body mass $\geq 7 \mathrm{~kg} ; n=845$ ). This assumes that larder data provide an unbiased sample of females and probability of being culled is not affected by reproductive status.

Captive female muntjac are capable of entering estrus 24 hours after giving birth and again 1 month later (Chapman et al. 1997); thus, the reproductive cycle for wild animals may be 7 or 8 months (Chapman et al. 1997). The lactation period in captive animals is up to 17 weeks (Chapman 1991), but may differ for free-ranging muntjac because of differences in stress, competition, nutrition, or weather. We initially assumed a fetus would be visible in the uterus 2 months after conception (see Appendix A, available online at www.onlinelibrary.wiley.- 


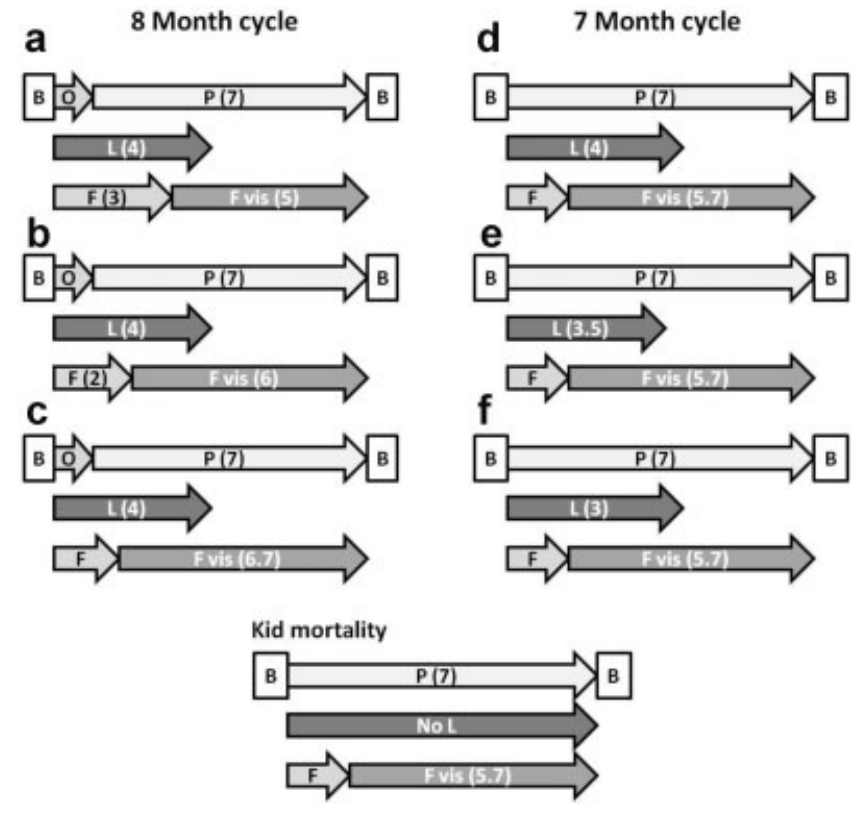

Figure 2. Schematic overview of models used to estimate neonatal survival of Reeve's muntjac from birth (B), showing gestation period $(\mathrm{P})$, changes in conception time $(\mathrm{O}=1 \mathrm{month})$, length of lactation period $(\mathrm{L})$, and whether a fetus is visible $\left(\mathrm{F}_{\mathrm{vis}}\right)$ or not upon opening the uterus. Values in parentheses show the duration of the stage in months $(\mathrm{F}=1.3$ months unless otherwise shown).

com). By comparing observed to expected proportions of lactating and pregnant females, we refined parameters for the gestation period, delay between birth and initiation of the next pregnancy, age from which the fetus is visible in the uterus, and the lactation period (Fig. 2). This supported the conclusion that the fetus is visible less than 2 months after conception, the duration of gestation is 7 months, and the lactation period is roughly 3.5 months (see Appendix A, available online at www.onlinelibrary.wiley.com).

\section{Analysis}

We calculated the potential net population growth $\mathrm{PPG}_{i(t+1)}$ (no. $/ \mathrm{km}^{2}$ ) from year $t$ to year $t+1$, in landscape unit $i$ as

$$
\mathrm{PPG}_{i(t+1)}=\frac{D_{i t} \times A_{i}+P_{i t+1}-M_{i t+1}}{A_{i}}-D_{i t}
$$

where $D_{i t}$ is the mean deer density $\left(\operatorname{deer} / \mathrm{km}^{2}\right)$ in year $t, A_{i}$ is the area $\left(\mathrm{km}^{2}\right)$ of the unit, $M_{i t+1}$ (individuals) is the annual cull, and $P_{i t+1}$ (individuals) is the total annual production for management unit $i$ in year $t$ calculated as

$$
P_{i t+1}=D_{F i t} \times A_{i} \times F_{t} \times S_{K}
$$

where $D_{F i t}$ is the mean adult female density for unit $i$ in year $t, F_{t}$ the fertility per female (landscape mean) in year $t$, and $S_{K}$ the neonatal survival (from birth to first winter) estimated from pooled data for cull years 2006-2009. We calculated mean adult female deer density $\left(D_{F i t}\right)$ per block as

$$
D_{F i t}=D_{i t} \times P_{\text {obs }} \times P_{\text {Fcull }}
$$

considering mean density $\left(D_{i t}\right)$, the mean proportion of female deer $\left(P_{\text {obs }}\right)$ recorded during thermal imaging surveys in 2008-2010, and the proportion of adult ( $\geq 2$ years) and yearling (1-2 years) roe females (excluding juveniles $<1$ year old) or the proportion of adult and reproductively active muntjac sub-adults within the cull of female individuals 2007-2009 ( $\left.P_{\text {Fcull }}\right)$.

We conducted sensitivity analyses of the predicted magnitude of source-sink flux for the population, accounting for stochastic variation and sampling error in parameter estimation. We sampled estimates for density, forest-wide fertility, and neonatal survival from normal distributions centered on the observed mean, with variance defined by the standard error of each parameter, separately in each of 1,000 model runs, using R (R Development Core Team 2010). For muntjac, we sampled neonatal survival from a uniform distribution bounded by the upper and lower range of likely values as the mean and variance were unknown (see Appendix A, available online at www.onlinelibrary.wiley.com). We estimated the relative contribution of each parameter to overall uncertainty in the estimate of potential sourcesink flux, by comparing the coefficient of variation resulting from the full model (with all parameters sampled) to a series of models in which only 1 parameter in turn was varied.

For roe, we validated interpretation of source-sink flux from this framework by comparing the observed female age structure (juvenile, yearling, adult) in the cull, to that predicted by a Leslie matrix model that assumed a closed population. We constructed the Leslie matrix in $\mathrm{R}$ and considered age-specific numbers, age-specific fertility (incorporating neonatal morality), and the proportionate cull to predict numbers of each class in the subsequent year. Each run of the model assumed a juvenile sex ratio of $50 \%$ and incorporated sampling error in estimates of population density, fertility, and neonatal mortality that were drawn from a normal distribution centered on the mean, with variance defined by the standard error of each parameter. We calculated the run-specific estimate of proportionate survival from the known cull and estimated density. For each run, we measured age structure after stabilizing (after the Leslie matrix was run for 40 years (Crawley 2007). As dispersal is expected to occur in younger age classes, particularly yearlings (Wahlstrom and Liberg 1995), discrepancy in age composition between the observed cull and model prediction should be consistent with estimates of either emigration (source) or immigration (sink). We did not construct Leslie matrix models of muntjac as the age of life-history stages based on body mass were unknown.

\section{RESULTS}

\section{Estimates of Age Structure, Productivity, and Neonatal Survival}

We determined the sex of individuals observed during thermal imaging surveys for $85 \%$ of roe in the forested and $94 \%$ of roe in the grass-heath landscape, and for $70 \%$ and $65 \%$ of muntjac, respectively. Sub-populations of both species were female biased. For muntjac, females comprised $59 \%$ of forest individuals sexed (2008-2010, $n=1,806)$ and $64 \%$ in the grass-heath (2009-2010, $n=196$, Fisher exact: $P<0.001$ ). 
Within forest larder data for female muntjac $(n=1,708)$, $66 \%$ were adults and $26 \%$ were sub-adults in 2006-2009; in grass-heath larder data $(n=293) 68 \%$ were adults and $23 \%$ were sub-adults in 2007-2009. Thus, reproductively active females comprised $54 \%$ (39\% adult, $15 \%$ sub-adult) of the forest and 59\% (44\% adult, 15\% sub-adult) of the grassheath muntjac sub-populations. For forest muntjac, annual mean fertility was 1.20 fetus per female \pm 0.07 95\% CL $(n=1,708 ; \quad$ sub-adult $=0.99 \pm 0.10 \quad 95 \% \quad \mathrm{CL}$; adult $=1.4 \pm 0.0595 \% \mathrm{CL}$ ), and in the grass-heath landscape fertility was 0.79 fetus per female $\pm 0.1695 \%$ CL (sub-adult $=0.45 \pm 0.24 \quad 95 \% \quad \mathrm{CL} ; \quad$ adult $=1.4 \pm 0.12$ 95\% CL).

For roe deer, females comprised $58 \%$ of forest individuals sexed $(n=1,023)$ and $67 \%$ in the grass-heath (Fisher exact: $P<0.001)$. Within forest larder data for female roe deer $(n=228), 73 \%$ were adults and $8 \%$ were yearlings; in grassheath larder data $(n=199) 45 \%$ were adults and $16 \%$ were yearlings in 2007-2009. Thus, reproductively active females comprised $47 \%$ ( $42 \%$ adult, $5 \%$ yearling) of the forest and $41 \%$ (30\% adult, $11 \%$ yearling) of the grass-heath roe deer sub-populations. We subsequently pooled landscape-specific fertility data across forest blocks $\left(\chi_{10}^{2}=14.31, P=0.14\right)$, years (forest: $\chi_{3}^{2}=1.57, P=0.67$; grass-heath: $\chi_{3}^{2}=0.38$, $P=0.83$ ) and for adults and yearlings (forest: $n=567$, $\chi_{1}^{2}=0.14, \quad P=0.71$; grass-heath: $n=47, \quad \chi_{1}^{2}=0.47$, $P=0.49$ ) in 2006-2009. For forest roe deer, the mean fertility was 1.50 fetus per female $\pm 0.08 \quad 95 \%$ CL $(n=331 ; \quad$ yearling $=1.16 \pm 0.27 \quad 95 \% \quad$ CL,$\quad n=37$; adult $=1.54 \pm 0.08$ 95\% CL; GLM controlling for year: $P=0.71)$ in 2006-2009. In the grass-heath, mean roe fertility was similar, at 1.47 fetus per female $\pm 0.2095 \% \mathrm{CL}$ $(n=47 ; \quad$ yearling $=1.25 \pm 0.39 \quad 95 \% \quad$ CL,$\quad n=12$; adult $=1.54 \pm 0.2495 \%$ CL; GLM controlling for year: $P=0.49)$ in $2007-2009$.

For roe deer, neonatal survival calculated from 481 femalejuvenile groups was $83 \% \pm 0.0495 \%$ CL in 2008 and in 2009. For muntjac, we examined neonatal mortality by comparing predicted to observed percentages of females lactating, with or without a fetus using different assumptions of mortality (see Appendix A, available online at www.onlinelibrary.wiley.com). Using the revised biological parameters, we found the greatest correlation between predicted and observed data for kid survival rates of $70 \%(R=1.0$, $P=0.003), \quad 65 \% \quad(R=1.0, \quad P=0.002), \quad$ and $\quad 60 \%$ $(R=0.99, P=0.004$; Fig. A.1, available online at www.onlinelibrary.wiley.com). We therefore used the median value of $65 \%$ neonatal survival in calculating source-sink flux, and explored values between $60 \%$ and $70 \%$ in sensitivity analyses.

\section{Deer Density Among Blocks and Between Landscapes}

Muntjac and roe deer densities were 3-5 times greater across the forested than in the grass-heath landscape (Fig. 3) and ranged 4-fold and 7-fold among forest blocks, respectively, in 2008-2010 (Figs. 4 and 5; GLMs, for muntjac, controlling for year and block $\times$ year interaction, block $F_{7,7}=34.97$, $P<0.001$; for roe deer, excluding non-significant effects of year and block $\times$ year, block $F_{8,15}=125.23, P<0.001$ ).

\section{Forest landscape}

\section{Muntjac}

\section{Grass-heath landscape}

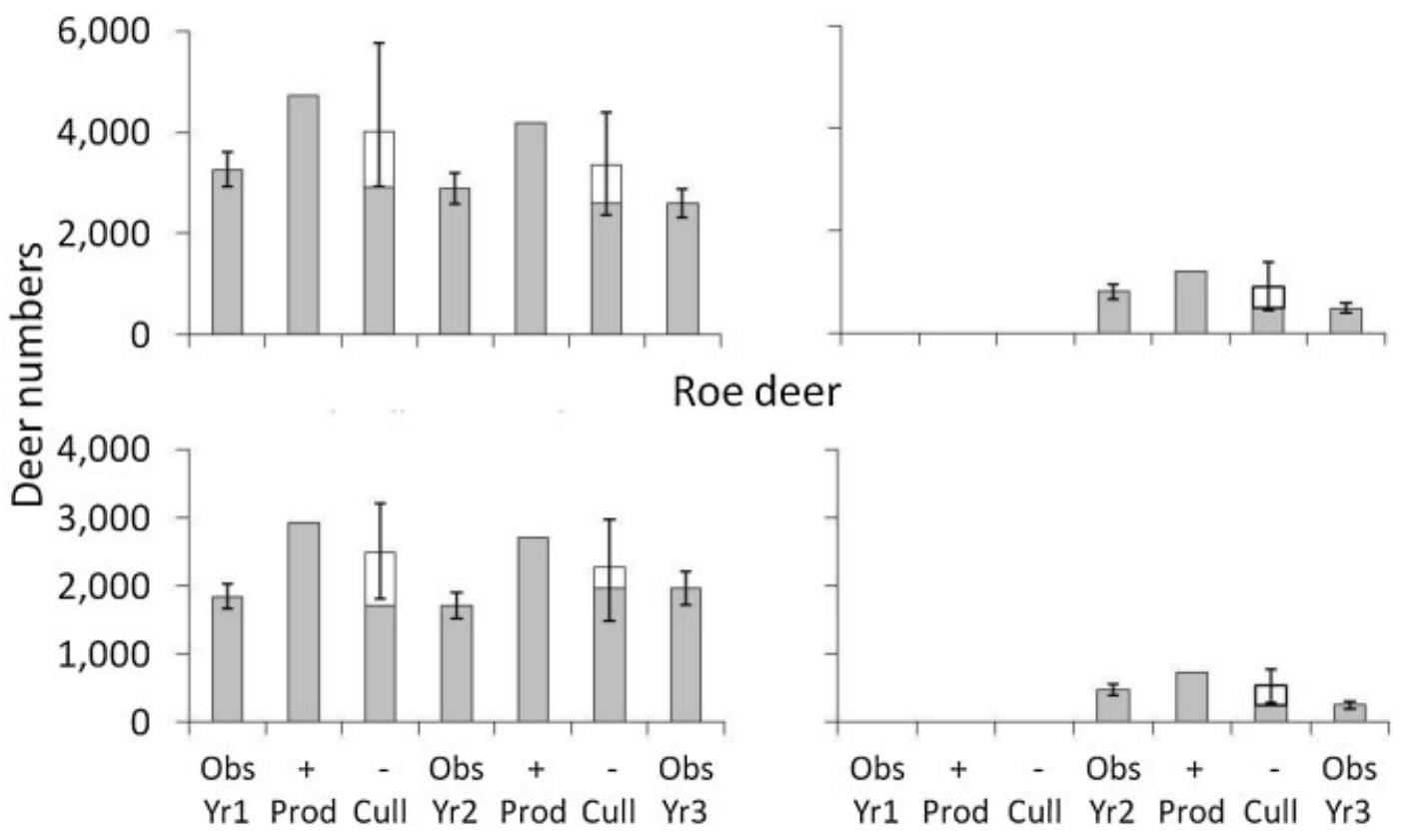

Figure 3. Estimates of deer numbers (Obs Yr; $\pm \mathrm{SE}$ ), potential population productivity ( + Prod), and cull intensity ( - Cull) of Reeve's muntjac and roe deer in 2008-2010 in Eastern England are shown separately for a forested landscape $\left(132 \mathrm{~km}^{2}\right)$ and a grass-heath landscape $\left(102 \mathrm{~km}^{2}\right)$. All years produced source populations, for which observed numbers are less than those predicted from fertility and cull, thus numbers emigrating (unshaded) are shown as part of the predicted numbers ( - Cull) 
Reeve's muntjac
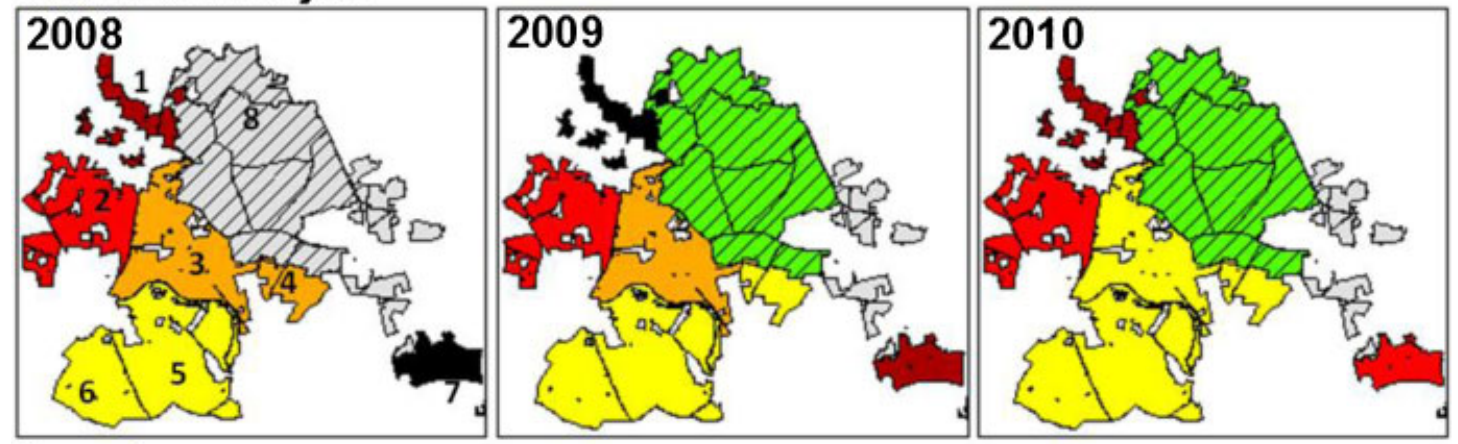

\section{Roe deer}
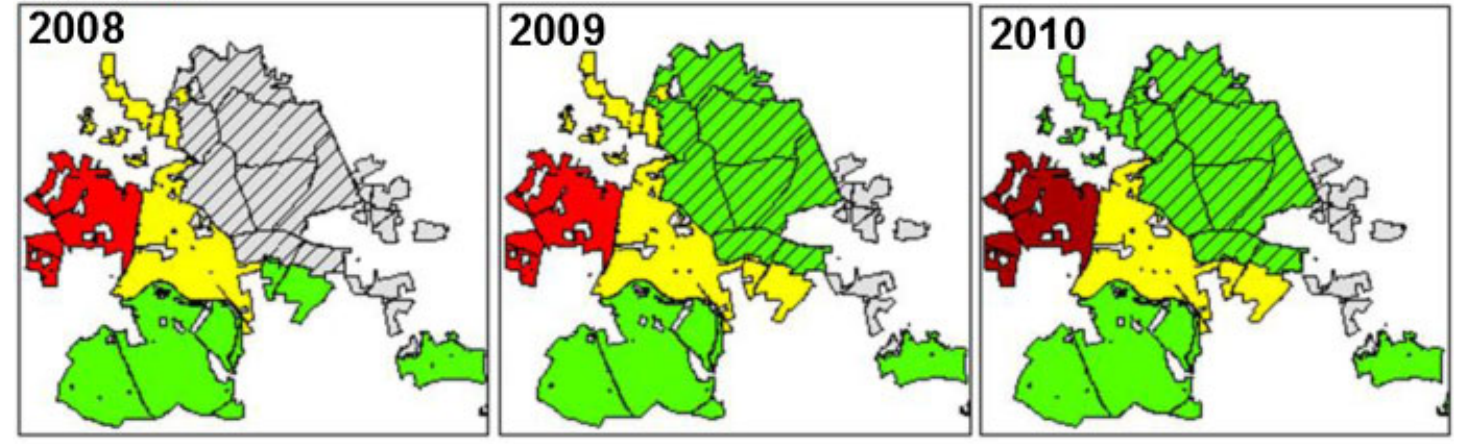

\section{Deer density [sq km]}

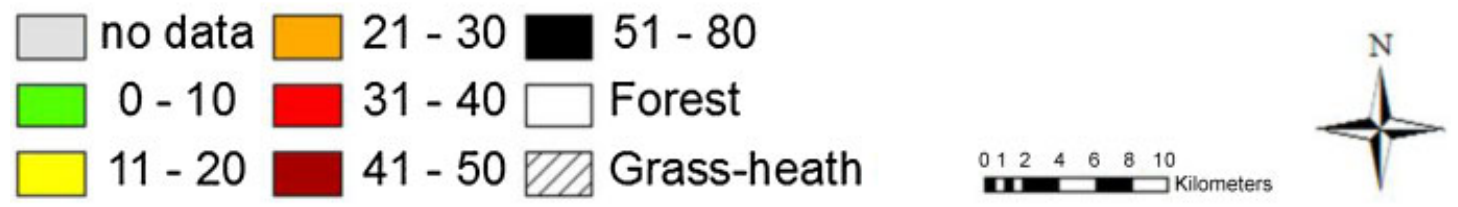

Figure 4. Spatial variation in densities (individuals $/ \mathrm{km}^{2}$ ) of Reeve's muntjac and roe deer in contiguous forested and grass-heath landscapes in 2008-2010 in Eastern England.

Muntjac density was progressively reduced by increased cull intensity in 2 of the 7 forest blocks (block 4: $P=0.01$, and 7 : $P<0.001)$, resulting in a significant overall effect of year (year: $F_{1,7}=48.56, P<0.001$ ) and a significant interaction between block and year $\left(F_{7,7}=26.08, P<0.001\right.$; Fig. 4$)$. In contrast, the pattern of roe density was stable among years (2008-2010; year: $F_{1,7}=0.64, P=0.45$; block $\times$ year: $\left.F_{7,7}=1.04, P=0.48\right)$.

\section{Effectiveness of Management: Sources and Sinks}

Cull targets underestimated deer population growth. In the forested landscape, for muntjac and roe deer the annual percentage of the sub-population culled (2008-2009: muntjac 23\%, roe 24\%; 2009-2010: muntjac 29\%, roe 26\%) was similar between 2008-2009 and 2009-2010, but much less than required to balance productivity and thus prevent emigration into the wider countryside (Figs. 2 and 3). The percentage of sub-populations culled in the grass-heath landscape differed only slightly to that achieved in the forest, for muntjac and roe it was $9 \%$ and $14 \%$ greater, respectively, in the grass-heath (Fig. 3). Potential net pop- ulation growth was therefore positive for both landscapes for both study periods for muntjac and roe deer (Figs. 2 and 3). To harvest the annual production, an annual cull of $53 \%$ of the muntjac and $60 \%$ of the roe deer sub-population would be necessary.

Population growth can vary at smaller scales within landscapes. Within the forest, mean values of potential annual population growth (2008-2009: 5.6 muntjac $/ \mathrm{km}^{2}$; 4.9 roe/ $\mathrm{km}^{2}$; 2009-2010: 3.6 muntjac $/ \mathrm{km}^{2}$; 4.2 roe $/ \mathrm{km}^{2}$ ) masked considerable heterogeneity among forest blocks. In both time periods, 1 forest block in particular showed substantially greater potential population growth for muntjac and another showed substantially greater potential population growth for roe deer (Fig. 5).

Positive population growth does not necessarily lead to increased density. Despite positive potential population growth in both landscapes, density did not increase. Thus, both landscapes acted as sources for roe and muntjac though contributions of individual forest blocks differed (Fig. 5). The forested landscape potentially exported 1,103 muntjac and 774 roe deer in 2008-2009 and both landscapes together 


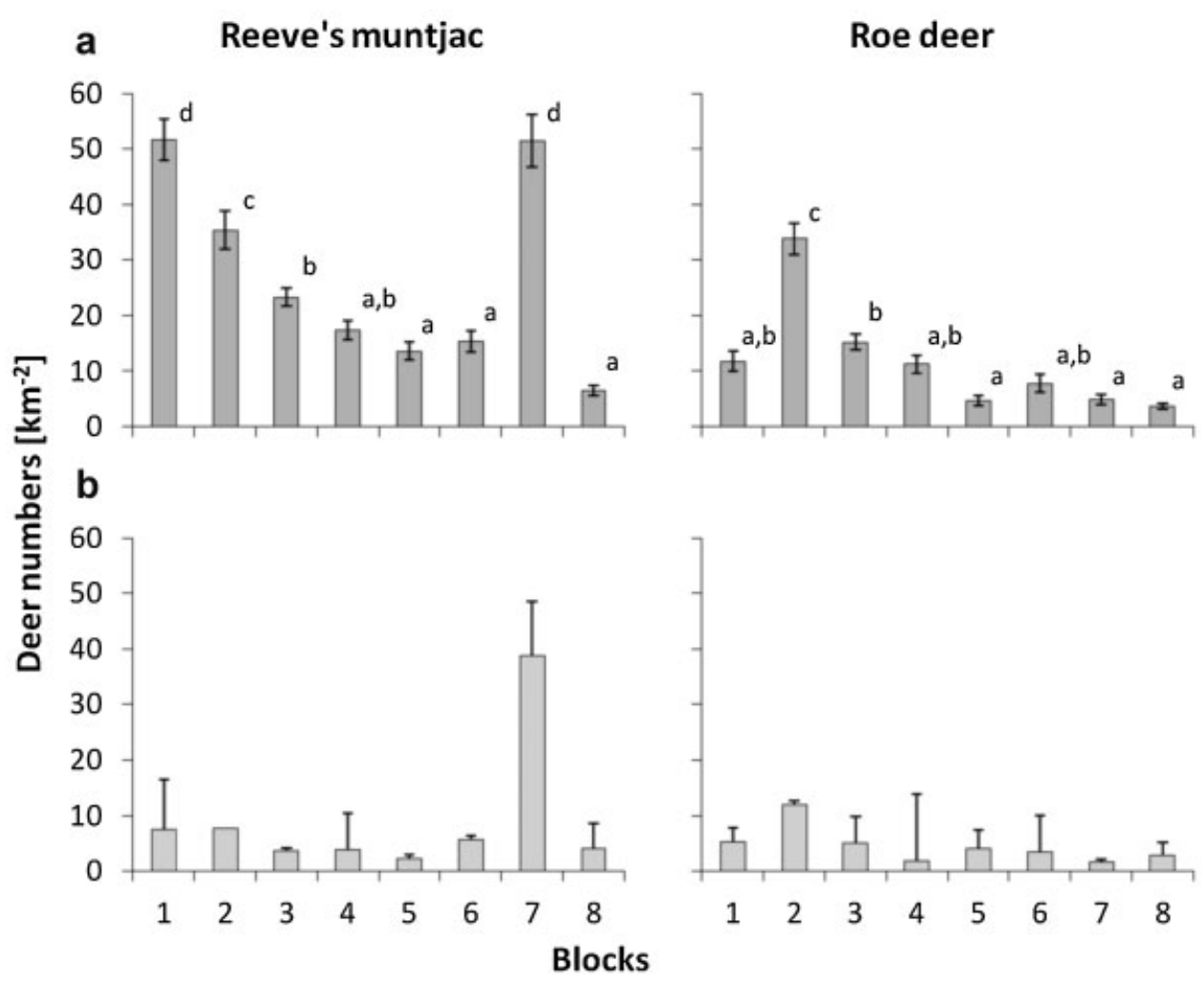

Figure 5. Estimates of (a) mean deer density ( $\pm 95 \% \mathrm{CI}$ ) and (b) mean source-sink flux ( $\pm 95 \% \mathrm{CI})$ in $2008-2010$ of Reeve's muntjac and roe deer in 7 forest blocks of the forested $\left(132 \mathrm{~km}^{2}\right)$ and in the grass-heath landscape (block $\left.8 ; 102 \mathrm{~km}^{2}\right)$ in Eastern England. Blocks with shared superscript do not differ in mean deer density (sequential Sidak test $P<0.05$ ).

potentially exported 1,287 muntjac and 584 roe in 2009 2010 (Fig. 3).

The majority of muntjac (69\%) emigrated from the forested landscape and both landscapes (forested landscape: 51\%; grass-heath landscape: 49\%) contributed to potential roe emigration in 2009-2010 (Fig. 3). In the forested landscape, sensitivity analysis for muntjac showed that although the upper and lower 95\% confidence intervals spanned a wide range, the forest acted as a source in 2008-2009 (95\% CI: 21 to 2,284$)$ and likely also in $2009-2010$ (95\% CI: -238 to $1,783)$. For roe deer the forest was a source in 2008-2009 but may have possibly acted as a weak sink or source in 20092010 (Fig. 3). Similarly, confidence bounds of population flux estimated for the grass-heath landscape were broad but showed that this landscape likely acted as a source for both muntjac and roe deer.

Source-sink flux can vary within short distances within 1 landscape. For muntjac, assuming a median rate of kid survival of $65 \%$, potential emigration-immigration rates ranged 10-fold among 7 forest blocks in both 2008-2009 and 2009-2010 (Fig. 5). A single small forest block $\left(9.8 \mathrm{~km}^{2}\right)$ that supported the greatest local density (71.2 deer $/ \mathrm{km}^{2}$ compared to 44.0 deer $/ \mathrm{km}^{2}$ in the next greatest block) contributed $33 \%$ of the total emigration across the $132 \mathrm{~km}^{2}$. This block continued to export large numbers of deer, despite a slight reduction in observed density that would lead a naive manager to assume that culling was effective. For roe deer, source-sink flux ranged 6-fold among forest blocks in 2008-2009 and 2009-2010 (Fig. 5). Again, a single forest block $\left(24.1 \mathrm{~km}^{2}\right)$ that supported the greatest local density ( $36.7 \mathrm{deer} / \mathrm{km}^{2}$ compared to $14.0 \mathrm{deer} / \mathrm{km}^{2}$ in the second greatest block) contributed to $37 \%$ of the total emigration across $132 \mathrm{~km}^{2}$ forest. Concentrating cull pressure on such key areas is necessary to reduce sources.

Comparing the coefficient of variation of the mean emigration rate resulting from the full model in 2008-2009 and 2009-2010 (forest muntjac: CV $=53 \%$ and $68 \%$, forest roe: $44 \%$ and $139 \%$, grass-heath muntjac: $\mathrm{CV}=60 \%$, grassheath roe: $45 \%$ ) with a series of models where only 1 parameter (density, fertility, or neonatal survival) was varied, showed that uncertainty in source-sink flux was largely influenced by uncertainty in estimated density (forest muntjac: $\mathrm{CV}=52 \%$ and $66 \%$, forest roe: $44 \%$ and $134 \%$, grassheath muntjac: $\mathrm{CV}=60 \%$, grass-heath roe: $45 \%)$ rather than neonatal survival (forest muntjac: $\mathrm{CV}<7 \%$, forest roe: $<9 \%$, grass-heath muntjac: $\mathrm{CV}<6 \%$, grass-heath roe: $<6 \%$ ) or fertility (in both landscapes muntjac: $\mathrm{CV}<5 \%$, roe: $<1 \%)$.

The observed percentage of adult roe females within larder data was $47 \%$ greater, and the observed proportion of yearling roe females (65\%) was less than that predicted by a Leslie matrix model that assumed a closed population (see Table B.1, available online at www.onlinelibrary.wiley.com). The 
younger age classes are not selectively culled; this discrepancy therefore supports the conclusion that both landscapes acted as a source for roe deer.

\section{DISCUSSION}

To our knowledge, this is the first time in any lowland European landscape that the effectiveness of deer cull management has been quantified to establish whether local management units contribute to reduced abundance across the wider landscape or continue to act as sources for further population increase and range expansion. In both forested and open landscapes, previous cull targets were based on assessments of population and damage, and density remained stable. Nonetheless, management was insufficient to prevent net population growth and both landscapes exported large numbers of deer, annually totaling 1,287 (-289-2,680) muntjac and $585(-454-1,533)$ roe deer. Without evidence-based management made possible by this study, Defence Estates would still be culling fewer animals and an extra 220 deer per annum would have emigrated into the wider landscape. Despite uncertainty due to sampling error in density estimates, both landscapes remained net sources for both species in sensitivity analysis. Areas of plantation forestry and woodland have considerable potential to act as regional sources, relative to lesser density populations in farmland (Gill et al. 1996). Our results are consistent with the ongoing and rapid range spread of both muntjac and roe deer in the United Kingdom (Ward 2005, Newson et al. 2012). Our findings elucidate the mechanisms required to address the continuing increase and spread of deer and the negative impacts associated with such change in the English landscape and Europe.

This study shows the need to base cull targets on an understanding of numbers and demography, not simply on impacts to features of interest. Basing targets on impacts has resulted in large numbers of deer being exported to cause problems in the wider landscape, without managers recognizing that this is occurring. This is emphasized by the finding that 1 small forest block experienced a decline in observed density, but continued to be one of the largest sources for emigrants. Sensitivity analyses showed that uncertainty in density was the greatest limitation to quantifying source-sink flux. However, assessing densities annually is not necessary; knowledge of density and recruitment rates in 1 year provide the starting point for management and numbers can then be re-surveyed after a period of elevated cull, for example, 3-4 years. Although thermal imaging equipment requires initial capital outlay, equipment can then be shared regionally to support coordinated deer management. For example, in the United Kingdom, the Forestry Commission and DEFRA Deer Initiative own such equipment and assist landowners in population assessments. Observed variance in fertility and neonatal survival had only minor effects on source-sink flux estimates. Although deer fertility and survival rates found in this study (Table B.1, available online at www.onlinelibrary.wiley.com) were within the range found elsewhere in the United Kingdom and Europe, for roe, these rates vary among regions (adult fertil- ity: $0.35-1.80$ fetus/doe; juvenile fertility: $0.30-1.60$; neonatal survival: 0.17-0.75; (Ratcliffe and Mayle 1992, Focardi et al. 2002). Thus, managers must establish regionally relevant demographic measures, particularly as effective control may result in density-dependent increases in fertility (Focardi et al. 2002, Pettorelli et al. 2003). Although this requires consistent measurement of reproductive parameters for culled individual, fetus counts in the uterus of culled females are straightforward and are routinely collected by many stalkers; further training for novice hunters is available from deer management groups. For kid survival, observation of roe family groups in autumn can be accomplished while stalking. To apply our source-sink framework will nevertheless require regionally coordinated data capture for both fertility and kid:doe counts. In contrast to the robust biological understanding of demographic parameters for most deer species present in Europe, for Reeve's muntjac, we needed to estimate reproductive parameters and neonatal mortality rates from observed frequencies of lactation and fetuses in culled individuals. Further research on this invasive species is required, particularly in view of the high densities at which it can occur (Hemami et al. 2005, 2007), its potential for biodiversity impacts (Dolman et al. 2010), and uncertainty in neonatal survival. We have demonstrated the potential to independently corroborate predictions of source-sink dynamics by comparing observed age structure to that predicted by a Leslie matrix model assuming a closed population.

\section{MANAGEMENT IMPLICATIONS}

This study shows that ignoring emigration-immigration rates can lead to misinformed management decisions (Pulliam 1988, Runge et al. 2006) with further negative consequences for biodiversity, biomass production, and road traffic accident rates across surrounding areas, many of which may not themselves be subject to adequate deer management. This requires wider recognition of source-sink dynamics by professional deer managers, landowners, stalkers, conservation managers, and the wider public. Although specifying what density will reduce impacts to an acceptable level is difficult, managers must continue to establish numbers to understand how many deer should be culled to reduce or stabilize a population. In management terms, successful reduction of deer numbers creates a problem of diminishing marginal returns; greater skill and effort are required to achieve a similar proportionate cull when density has been reduced to low levels. In such situations, effectiveness is greatly enhanced by detailed knowledge of the stalking area and local opportunities for achieving control. Whether this is best achieved by recreational hunting or by professional deer managers and under what situations has yet to be determined. Across the forested area of our study $\left(132 \mathrm{~km}^{2}\right)$ a mean annual cull of 1523 muntjac from the estimated population of 2,873 individuals (53\%) and 1,106 roe from the estimated population of 1,844 individuals (60\%) would be necessary to offset productivity. These rates greatly exceed previous cull recommendations, $30 \%$ for muntjac and $20 \%$ for roe (The Deer Initiative 2010). We have shown the clear necessity of an evidence-based approach to deer man- 
agement with an understanding of population numbers to prevent population increases and exporting problems to the surrounding landscape. Assumptions about appropriate and sufficient levels of control based on perceived numbers, impacts, and apparent stability can exacerbate problems at the wider regional scale.

\section{ACKNOWLEDGMENTS}

This study was funded by the University East Anglia and the Forestry Commission England with support from the Deer Initiative, Defence Estates, and the St. Hubert Hunting Club. We are grateful to the wildlife ranger team of Thetford Forest, T. Banham, B. Ball, D. Gunn, S. Hetherington, P. Mason, and T. Parr; to B. Monckton of the Defence Estates for advice and assistance; and to D. Euler, A. Tanentzap, and an anonymous reviewer for valuable comments on an earlier draft of this paper.

\section{LITERATURE CITED}

Aitken, R. J. 1974. Delayed implantation in roe deer (Capreolus capreolus). Journal of Reproduction and Fertility 39:225-233.

Allombert, S., S. Stockton, and J. L. Martin. 2005. A natural experiment on the impact of overabundant deer on forest invertebrates. Conservation Biology 19:1917-1929.

Apollonio, M., R. Andersen, and R. J. Putman, editors. 2010. European ungulates and their management in the 21st century. Cambridge University Press, Cambridge, United Kingdom.

Bruinderink, G. and E. Hazebroek. 1996. Ungulate traffic collisions in Europe. Conservation Biology 10:1059-1067.

Buckland, S. T. D. R. Anderson, K. P. Burnham, J. L. Laake, D. L. Borchers, and L. Thomas. 2001. Introduction to distance samplingestimating abundance of biological populations. Oxford University Press, Oxford, United Kingdom.

Buesching, C. D., C. Newman, J. T. Jones, and D. W. Macdonald. 2011. Testing the effects of deer grazing on two woodland rodents, bankvoles and woodmice. Basic and Applied Ecology 12:207-214.

Chapman, D. I., N. G. Chapman, and C. M. Colles. 1985. Tooth eruption in Reeve's muntjac (Muntiacus reevesi) and its use as a method of age estimation (Mammalia, Cervidae). Journal of Zoology 205:205-221.

Chapman, N. G. 1991. Chinese muntjac Muntiacus reevesi. Pages 526-532 in G. B. Corbet and S. Harris, editors. The handbook of British mammals. Blackwell Scientific, Oxford, United Kingdom.

Chapman, N. G., M. Furlong, and S. Harris. 1997. Reproductive strategies and the influence of date of birth on growth and sexual development of an aseasonally-breeding ungulate: Reeves' muntjac (Muntiacus reevesi). Journal of Zoology 241:551-570.

Chee, Y. E. and B. A. Wintle. 2010. Linking modelling, monitoring and management: an integrated approach to controlling overabundant wildlife. Journal of Applied Ecology 47:1169-1178.

Crawley, M. J. 2007. The R book. John Wiley, New York, New York, USA.

DeCalesta, D. S. 1994. Effects of white-tailed deer on songbirds within managed forests in Pennsylvania. Journal of Wildlife Management 58:711-718.

Department for Environment, Food \& Rural Affairs [DEFRA] and Forestry Commission. 2010. The sustainable management of wild deer populations in England: a review of 2005-2008 and summary of action to March 2011. The Deer Initiative, Wrexham, United Kingdom.

Dolman, P. M., R. J. Fuller, R. M. A. Gill, D. Hooton, and R. Tabor. 2010. Escalating ecological impacts of deer in lowland woodland. British Wildlife 21:242-254.

Dolman, P. M., C. J. Panter, and H. L. Mossman. 2012. The biodiversity audit approach challenges regional priorities and identifies a mismatch in conservation. Journal of Applied Ecology 49:986-997.

Dolman, P. M. and K. Wäber. 2008. Ecosystem and competition impacts of introduced deer. Wildlife Research 35:202-214.
Eycott, A. E., A. R. Watkinson, and P. M. Dolman. 2006. Ecological patterns of plant diversity in a plantation forest managed by clearfelling. Journal of Applied Ecology 43:1160-1171.

Focardi, S., E. R. Pelliccioni, R. Petrucco, and S. Toso. 2002. Spatial patterns and density dependence in the dynamics of a roe deer (Capreolus capreolus) population in central Italy. Oecologia 130:411-419.

Fuller, R. J. and P. Rothery. 2010. Woodfuel management: prospects for reversing declines in woodland birds. BOU Proceedings 2010-Climate Change and Birds: $1-4$.

Gaillard, J. M., A. Loison, and C. Toigo. 2003. Variation in life history traits and realistic population models for wildlife management. Pages 115-132 in M. Festa-Bianchet and M. Apollonio, editors. Animal behaviour and wildlife conservation. Island Press, Washington, D.C., USA.

Gill, R. M. A., A. L. Johnson, A. Francis, K. Hiscocks, and A. J. Peace. 1996. Changes in roe deer (Capreolus capreolus L) population density in response to forest habitat succession. Forest Ecology and Management 88:31-41.

Gill, R. M. A., M. L. Thomas, and D. Stocker. 1997. The use of portable thermal imaging for estimating deer population density in forest habitats. Journal of Applied Ecology 34:1273-1286.

Glista, D. J., T. L. DeVault, and J. A. DeWoody. 2009. A review of mitigation measures for reducing wildlife mortality on roadways. Landscape and Urban Planning 91:1-7.

Hartfield, M., K. A. J. White, and K. Kurtenbach. 2011. The role of deer in facilitating the spatial spread of the pathogen Borrelia burgdorferi. Theoretical Ecology 4:27-36.

Hemami, M. R., A. R. Watkinson, and P. M. Dolman. 2005. Population densities and habitat associations of introduced muntjac Muntiacus reevesi and native roe deer Capreolus capreolus in a lowland pine forest. Forest Ecology and Management 215:224-238.

Hemami, M. R., A. R. Watkinson, R. M. A. Gill, and P. M. Dolman. 2007. Estimating abundance of introduced Chinese muntjac Muntiacus reevesi and native roe deer Capreolus capreolus using portable thermal imaging equipment. Mammal Review 37:246-254.

Holt, C. A., R. J. Fuller, and P. M. Dolman. 2011. Breeding and postbreeding responses of woodland birds to modification of habitat structure by deer. Biological Conservation 144:2151-2162.

Koda, R. and N. Fujita. 2011. Is deer herbivory directly proportional to deer population density? Comparison of deer feeding frequencies among six forests with different deer density. Forest Ecology and Management 262:432-439.

Martin, J. L., S. A. Stockton, S. Allombert, and A. J. Gaston. 2010. Topdown and bottom-up consequences of unchecked ungulate browsing on plant and animal diversity in temperate forests: lessons from a deer introduction. Biological Invasions 12:353-371.

Martin, T. G., P. Arcese, and N. Scheerder. 2011. Browsing down our natural heritage: deer impacts on vegetation structure and songbird populations across an island archipelago. Biological Conservation 144:459-469.

Mayle, B. A. 1996. Progress in predictive management of deer populations in British woodlands. Forest Ecology and Management 88:187-198.

Morellet, N., J-M. Gaillard, A. J. M. Hewison, P. Ballon, Y. Boscardin, P. Duncan, F. Klein, and D. Maillard. 2007. Indicators of ecological change: new tools for managing populations of large herbivores. Journal of Applied Ecology 44:634-643.

Mysterud, A., H. Askilsrud, L. E. Loe, and V. Veiberg. 2010. Spatial patterns of accumulated browsing and its relevance for management of red deer Cervus elaphus. Wildlife Biology 16:162-172.

Newson, S. E., A. Johnston, A. R. Renwick, S. R. Baillie, and R. J. Fuller. 2012. Modelling large-scale relationships between changes in woodland deer and bird populations. Journal of Applied Ecology 49:278-286.

Pettorelli, N., J.-M. Gaillard, P. Duncan, D. Maillard, G. van Laere, and D. Delorme. 2003. Age and density modify the effects of habitat quality on survival and movements of roe deer. Ecology 84:3307-3316.

Pulliam, H. R. 1988. Sources, sinks, and population regulation. American Naturalist 132:652-661.

Putman, R. J. 2012. Effects of heavy localised culling on population distribution of red deer at landscape scale: an analytical modelling approach. European Journal of Wildlife Research 58:781-796.

Putman, R. J., J. Langbein, P. Green, and P. Watson. 2011. Identifying threshold densities for wild deer in the UK above which negative impacts may occur. Mammal Review 41:175-196. 
R Development Core Team. 2010. R: a language and environment for statistical computing. R Foundation for Statistical Computing, Vienna, Austria.

Ratcliffe, P. R. and B. A. Mayle. 1992. Roe deer biology and management. Forestry Commission Bulletin 105:1-28.

Runge, J. P., M. C. Runge, and J. D. Nichols. 2006. The role of local populations within a landscape context: defining and classifying sources and sinks. American Naturalist 167:925-938.

Suominen, O. and K. Danell. 2006. Effects of large herbivores on other fauna. Pages 383-412 in K. Danell, R. Bergstrom, P. Duncan, and J. Pastor, editors. Large herbivore ecology, ecosystem dynamics and conservation. Cambridge University Press, Cambridge, United Kingdom.

Tanentzap, A. J., D. R. Bazely, S. Koh, M. Timciska, E. G. Haggith, T. J. Carleton, and D. A. Coomes. 2011. Seeing the forest for the deer: do reductions in deer-disturbance lead to forest recovery? Biological Conservation 144:376-382.

Tanentzap, A. J., L. E. Burrows, W. G. Lee, G. Nugent, J. M. Maxwell, and D. A. Coomes. 2009. Landscape-level vegetation recovery from herbivory: progress after four decades of invasive red deer control. Journal of Applied Ecology 46:1064-1072.

Tanentzap, A. J. and D. A. Coomes. 2012. Carbon storage in terrestrial ecosystems: do browsing and grazing herbivores matter? Biological Reviews 87:72-94.
Tanentzap, A. J., K. J. Kirby, and E. Goldberg. 2012. Slow responses of ecosystems to reductions in deer (Cervidae) populations and strategies for achieving recovery. Forest Ecology and Management 264: 159-166.

The Deer Initiative. 2010. Deer best practice guides-England and Wales. The Deer Initiative, Shrewsbury, United Kingdom.

Thomas, L., S. T. Buckland, E. A. Rexstad, J. L. Laake, S. Strindberg, S. L. Hedley, J. R. B. Bishop, T. A. Marques, and K. P. Burnham. 2010. Distance software: design and analysis of distance sampling surveys for estimating population size. Journal of Applied Ecology 47:5-14.

Wahlstrom, L. K. and O. Liberg. 1995. Patterns of dispersal and seasonal migration in roe deer (Capreolus capreolus). Journal of Zoology 235:455467.

Ward, A. I. 2005. Expanding ranges of wild and feral deer in Great Britain. Mammal Review 35:165-173.

Zannèse, A., N. Morellet, C. Targhetta, A. Coulson, S. Fuser, A. J. M. Hewison, and M. Ramanzin. 2006. Spatial structure of roe deer populations: towards defining management units at a landscape scale. Journal of Applied Ecology 43:1087-1097.

Associate Editor: David Euler. 